\begin{tabular}{|c|c|}
\hline Title & Nitrogen-Rich Manganese Oxynitrides with Enhanced Catalytic A ctivity in the Oxygen Reduction Reaction \\
\hline Author(s) & Miura, A kira; Rosero-Navarro, Carolina; Masubuchi, Y uji; Higuchi, Mikio; Kikkawa, Shinichi; Tadanaga, Kiyoharu \\
\hline Citation & $\begin{array}{l}\text { A ngew andte Chemie International Edition, 55(28), 7963- } 7967 \\
\text { https://doi.org/10.1002/anie.201601568 }\end{array}$ \\
\hline Issue Date & 2016-05-19 \\
\hline Doc URL & http:/hdl.handle.net/2115/65491 \\
\hline Rights & $\begin{array}{l}\text { This is the peer reviewed version of the following article: Nitrogen-Rich Manganese Oxynitrides with Enhanced } \\
\text { Catalytic A ctivity in the Oxygen Reduction Reaction, which has been published in final form at } \\
\text { http://dx.doi.org/10.1002/anie.201601568. This article may be used for non-commercial purposes in accordance with } \\
\text { Wiley Terms and Conditions for Self-A rchiving. }\end{array}$ \\
\hline Type & article (author version) \\
\hline Additional Information & There are other files related to this item in HUSCA P. Check the above URL. \\
\hline File Information & A ngewandte_7_revise_Saishuban1.pdf \\
\hline
\end{tabular}

Instructions for use 


\section{HOKKAIDO UNIVERSITY}

\begin{tabular}{|c|c|}
\hline Title & $\begin{array}{l}\text { Nitrogen-Rich Manganese Oxynitrides with Enhanced } \\
\text { Catalytic Activity in the Oxygen Reduction Reaction }\end{array}$ \\
\hline Author(s) & $\begin{array}{l}\text { Miura, A kira; Rosero-Navarro, Carolina; Masubuchi, Y uji; } \\
\text { Higuchi, Mikio; Kikkawa, Shinichi; T adanaga, Kiyoharu }\end{array}$ \\
\hline Citation & A ngew andte Chemie International Edition \\
\hline Issue Date & 2016-05-19 \\
\hline DOI & \\
\hline Doc URL & http://hdl.handle.net/2115/65491 \\
\hline Right & $\begin{array}{l}\text { This is the peer reviewed version of the following article: } \\
\text { Nitrogen-Rich M anganese Oxynitrides with Enhanced } \\
\text { Catalytic A ctivity in the Oxygen Reduction Reaction, which } \\
\text { has been published in final form at } \\
\text { http://dx.doi.org/10.1002/anie.201601568. This article may be } \\
\text { used for non-commercial purposes in accordance with Wiley } \\
\text { Terms and Conditions for Self-A rchiving. }\end{array}$ \\
\hline Type & article (author version) \\
\hline $\begin{array}{l}\text { Additional } \\
\text { Information }\end{array}$ & $\begin{array}{l}\text { There are other files related to this item in HUSCAP. Check the } \\
\text { above URL. }\end{array}$ \\
\hline $\begin{array}{c}\text { File } \\
\text { Information }\end{array}$ & A ngewandte_7_revise_最終版1.pdf (本文) \\
\hline
\end{tabular}

Instructions for use 


\title{
Nitrogen-Rich Manganese Oxynitrides with Enhanced Catalytic Activity in the Oxygen Reduction Reaction
}

\author{
Akira Miura, * Carolina Rosero-Navarro, Yuji Masubuchi, Mikio Higuchi, Shinichi Kikkawa, and \\ Kiyoharu Tadanaga
}

\begin{abstract}
The catalytic activity of manganese oxynitrides in the oxygen reduction reaction (ORR) was investigated in alkaline solutions to clarify the effect of nitrogen on ORR activity. These oxynitrides, having rocksalt-based structures with different nitrogen content, were synthesized by reactions of $\mathrm{MnO}, \mathrm{Mn}_{2} \mathrm{O}_{3}$, and $\mathrm{MnO}_{2}$ with molten $\mathrm{NaNH}_{2}$ at $240-280{ }^{\circ} \mathrm{C}$. Anion contents and $\mathrm{Mn}$ valence states were determined by combustion analysis, powder X-ray diffraction, and X-ray absorption near edge structure analysis. An increase in nitrogen content in rocksaltbased manganese oxynitrides enhanced the valence of manganese and reinforced the catalytic activity for the ORR in 1 $\mathrm{M} \mathrm{KOH}$ solution. Nearly single-electron occupancy in antibonding $e_{\mathrm{g}}$ states and high covalency in $\mathrm{Mn}-\mathrm{N}$ bonding would enhance the ORR activity of nitrogen-rich manganese oxynitrides.
\end{abstract}

Catalysts for the oxygen reduction reaction (ORR) in alkaline solutions $\left(\mathrm{O}_{2}+2 \mathrm{H}_{2} \mathrm{O}+4 \mathrm{e}^{-} \rightarrow{ }_{4} \mathrm{OH}^{-}\right)$are key materials for nextgeneration energy conversion and storage systems, including fuel cells and metal-air batteries, and highly efficient ORR catalysts are highly desirable. ${ }^{[1]}$ A group of well-studied catalysts includes perovskite oxides, such as $\mathrm{LaCoO}_{3}$ and $\mathrm{LaMnO}_{3}$, whose structure-activity correlation has been extensively explored. ${ }^{[1-2]}$ Although the ORR is mechanistically complicated and is influenced by crystal structure, composition, electronic conductivity, surface absorption behavior, and the incorporation of conductive additives, ${ }^{[1 a]}$ the structure-activity correlation gives the rational guidelines for designing and understanding ORR catalysts.

Nitrides and related compounds have been studied as ORR catalysts. Binary and ternary nitrides, such as $\mathrm{AlN}, \mathrm{TiN}, \mathrm{Cu}_{3} \mathrm{~N}$, and $\mathrm{Cu}_{3} \mathrm{PdN}$, show catalytic activity for the ORR. ${ }^{[3]}$ Oxynitrides, including $\mathrm{ZrO}_{\mathrm{x}} \mathrm{N}_{\mathrm{y}}, \mathrm{MoO}_{\mathrm{x}} \mathrm{N}_{\mathrm{y}}, \mathrm{TaO}_{\mathrm{x}} \mathrm{N}_{\mathrm{y}}$ and $\mathrm{CoMoO}_{\mathrm{x}} \mathrm{N}_{\mathrm{y}}$, also show the catalytic activity. ${ }^{[4]}$ Nonetheless, the correlation between structure and ORR activity has not been extensively studied, and the role of nitrogen in altering catalytic activity is not completely understood. The challenge would be the difficulty of tuning the amount of incorporated nitrogen, mainly due to the thermodynamic stability of the triple bond in molecular $\mathrm{N}_{2}$. Additionally, the different nitrogen amount often has a significant effect on the crystal structure of synthesized products, ${ }^{[5]}$ thus complicating the interpretation of results.

Pervoskite oxides contain metal-oxygen octahedron, whose electronic structure can be schematically depicted as $t_{\mathrm{g}}$ and $e_{\mathrm{g}}$ states. Suntivich et al. have reported that nearly single-electron occupancy in $e_{\mathrm{g}}$ states composed by antibonding metal-oxygen interaction is beneficial for an electron transfer during the ORR cycle.[2d]; a typical example of a single electron in $e_{\mathrm{g}}$ states is $\mathrm{LaMnO}_{3}$ with trivalent manganese. Additionally, more covalency of metal-oxygen bonding in perovskite oxides is favorable for the ORR . [2c, 2d] Since nitrogen has less electron than oxygen and metal-nitrogen bonding is more covalent than metal-oxygen one, the tuning of nitrogen content can change its electronc structure, and thus enhance the ORR activity. Oxynitrides with rocksalt-based structure contain metal-anion octahedron, and thus its electronic structure would be similar to that of perovskite oxides. Both $\mathrm{MnO}$ and $\mathrm{MnN}_{x}(x \geq 2 / 3)$ adopt rocksalt-based structures, ${ }^{[6]}$ and the Fermi level of stoichiometric $\mathrm{MnN}$ is computationally predicted to be located near the boundary between bonding and antibonding states. ${ }^{[7]}$ Therefore, manganese oxynitrides with different anion contents are suitable octahedral motif to examine the effect of nitrogen on ORR activity. In this work, we examined the composition, structures, valence states, and ORR activity of three manganese oxynitrides having rocksalt-based structures with different $\mathrm{O} / \mathrm{N}$ anion ratios. Tuning of the incorporated nitrogen amount in rocksalt-based structures was achieved using the recently developed low-temperature nitridation of manganese oxides by sodium amide. ${ }^{[8]}$ It was found that the ORR activities of nitrogen-rich manganese oxynitrides were higher than those of less nitrogen oxynitride and manganese monoxide.

Black manganese oxynitrides prepared by the above method using an alkaline molten salt, sodium amide, are highly stable towards bases, which is a pre-requisite for ORR catalysts in alkaline solutions. Nitridation of $\mathrm{Mn}_{2} \mathrm{O}_{3}, \mathrm{MnO}_{2}$, and $\mathrm{MnO}$ powders gave three different manganese oxynitrides, described as $\operatorname{MnON}(1), \quad \operatorname{MnON}(2)$, and $\operatorname{MnON}(3)$, respectively. Combustion analysis revealed the highest nitrogen content for $\operatorname{MnON}(1)$, followed by $\operatorname{MnON}(2)$, and $\operatorname{MnON}(3)$ (Table 1 ). Energy dispersive X-ray spectroscopy showed peaks of nitrogen, oxygen, and manganese, with a small peak attributable to sodium; the $\mathrm{Na} / \mathrm{Mn}$ ratio was semi-quantitatively estimated to be $\leq$.o.o1.

SEM images of manganese oxynitride powders showed the aggregates of less than a few micron in size (Figure $1 \mathrm{a}-\mathrm{d}$ ). The size of the primary particles estimated from TEM observation are approximately 30-100 $\mathrm{nm}$ in size for $\mathrm{MnON}(1), 80-150 \mathrm{~nm}$ for $\mathrm{MnON}(2)$ and $50-300 \mathrm{~nm}$ for $\mathrm{MnON}(3)$ and $\mathrm{MnO}$. Electron diffraction images show diffraction spots, which can be assigned as strong diffractions of rocksalt structures. 
Table 1. Structural summary of manganese oxynitrides.

\begin{tabular}{|c|c|c|c|}
\hline & $\operatorname{MnON}(1)$ & $\operatorname{MnON}(2)$ & $\mathrm{MnON}(3)$ \\
\hline Mn:O:N molar ratio ${ }^{[a]}$ & 1:0.24:0.84 & 1:0.19:0.78 & 1:0.19:0.64 \\
\hline Space group & $I_{4} / \mathrm{mmm}$ & $I_{4} / \mathrm{mmm}$ & $I_{4} / \mathrm{mmm}$ \\
\hline Unit cell / nm & $\begin{array}{l}a=0.298163(10) \\
c=0.414716(14)\end{array}$ & $\begin{array}{l}a=0.297592(12) \\
c=0.410434(16)\end{array}$ & $\begin{array}{l}a=0.297355(7) \\
c=1.21520(4)\end{array}$ \\
\hline $\mathrm{Mn}_{4}(\mathrm{O}, \mathrm{N})_{4} \operatorname{cell}^{[\mathrm{b}]} / \mathrm{nm}$ & $\begin{array}{l}a=0.421673(14) \\
c=0.414716(14)\end{array}$ & $\begin{array}{l}a=0.420866(16) \\
c=0.410434(16)\end{array}$ & $\begin{array}{l}a=0.420530(10) \\
c=0.405067(13)\end{array}$ \\
\hline Occupancy of $(\mathrm{O}, \mathrm{N})$ site $^{[\mathrm{c}]}$ & $0.998(6)$ & o.889(9) & $0.779(1)$ \\
\hline Na-birnessite $[\mathrm{d}] /$ wt $\%$ & 1.5 & 2.6 & 2.5 \\
\hline $\mathrm{Mn}(\mathrm{OH})_{2}{ }^{[\mathrm{d}]} / \mathrm{wt} \%$ & o & o & 1.5 \\
\hline$R_{\mathrm{wp}} / \%$ & 8.95 & 11.9 & 14.2 \\
\hline$S$ & 1.20 & 1.67 & 1.65 \\
\hline Mn valence ${ }^{[\mathrm{e}]}$ & 3.0 & 2.8 & 2.4 \\
\hline
\end{tabular}

[a] Combustion analysis; calculated from measured values for $\mathrm{N}$ and $\mathrm{O}$, and residuals for $\mathrm{Mn}$.

[b] $\mathrm{Mn}_{4}(\mathrm{O}, \mathrm{N})_{4}$ unit cells are visualized for comparison of their lattice parameters (Figure 2).

[c] Derived by Rietveld analysis assuming that anion sites are occupied by only nitrogen and cation sites are fully occupied by manganese. The occupancy quoted for $\mathrm{MnON}(3)$ is the total occupancy of two anion sites.

[d] Derived from Rietveld analysis: $\mathrm{Na}_{0.364} \mathrm{MnO}_{2}\left(\mathrm{H}_{2} \mathrm{O}\right)_{0.544}$ (ICSD \#966o6), $\mathrm{Mn}(\mathrm{OH})_{2}(\mathrm{ICSD} \# 23591)$

[e] Estimated values from X-ray absorption $K$-edge of $\mathrm{Mn}$.
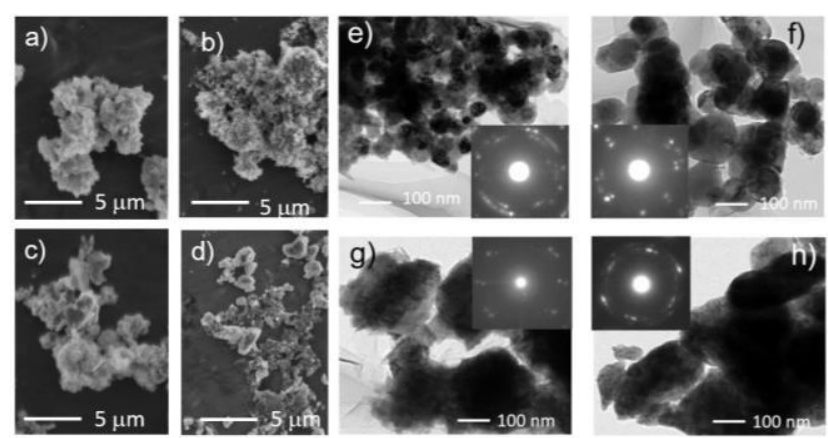

Figure 1. SEM images of a) $\mathrm{MnON}(1)$, b) $\mathrm{MnON}(2)$, c) $\mathrm{MnON}(3)$ and d) $\mathrm{MnO}$; TEM and electron diffraction images of e) $\mathrm{MnON}(1), \mathrm{f}$ ) $\mathrm{MnON}(2), g) \mathrm{MnON}(3)$ and $\mathrm{h}) \mathrm{MnO}$.

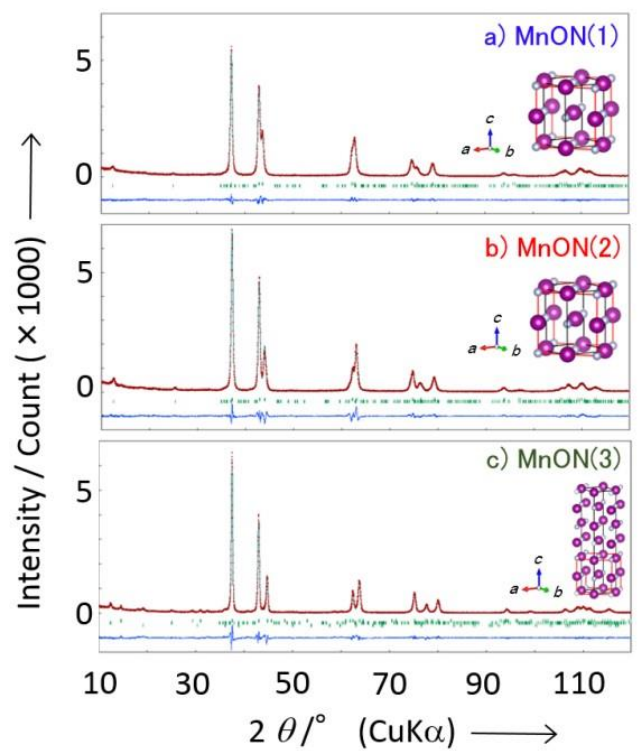

Figure 2. Rietveld profiles of $\mathrm{X}$-ray diffraction of a) $\mathrm{MnON}(1)$, b) $\mathrm{MnON}(2)$, and c) MnON(3). Bars indicate the calculated positions of Bragg peaks and bottom lines represent residuals. Insets show cell structural models: large and small spheres represent $\mathrm{Mn}$ and $\mathrm{O} / \mathrm{N}$ sites, respectively. Lines represent unit cell boundaries and the $\mathrm{Mn}_{4}(\mathrm{O}, \mathrm{N})_{4}$ cell.
The X-ray diffraction (XRD) patterns of manganese oxynitrides are shown in Figure 2 and Rietveld refinement results are summarized in Table 1 . Major diffraction peaks attributable to rocksalt structures and minor peaks attributable to Na-birnessite and $\mathrm{Mn}(\mathrm{OH})_{2}$ were detected. The oxynitrides have tetragonal structures featuring a Mn$(\mathrm{O}, \mathrm{N})$ octahedron, with the c-axis slightly shorter than the $a$ and $b$-axes. $\operatorname{MnON}(3)$, having the lowest nitrogen content, has a three-fold superlattice along the $c$-axis with ordered anion vacancies; weak superlattice spots were confirmed by electron diffraction (Figure $\mathrm{S} 1$ ). For comparison, let us take the cell of $\mathrm{Mn}_{4}(\mathrm{O}, \mathrm{N})_{4}$ to be similar to the unit cell of the cubic rocksalt structure. An increase of nitrogen content from $\mathrm{MnON}(3)$ to $\mathrm{MnON}(1)$ shifted the diffraction peaks toward lower angle, which corresponded to the increase of the lattice parameters. Three manganese oxynitrides showed different relative intensities of the peaks. Freely refined occupancy of anion sites via Rietveld refinements suggested that the increase in nitrogen content increased the occupancy of anion sites. Figure 3 shows the X-ray absorption $K$-edge of $\mathrm{Mn}$. The absorption edge was shifted toward higher energies with increasing nitrogen content, suggesting an increased $\mathrm{Mn}$ valence from 2.4 to 3.0 in the synthesized oxynitride powders. The surface of manganese oxynitrides was examined by X-ray photoelectron spectroscopy (XPS). In three manganese oxynitrides, $\mathrm{O}$ and $\mathrm{N}$ signals were detected at 529.5 and 395.8 $\mathrm{eV}$, respectively, suggesting $\mathrm{Mn}-\mathrm{O}$ and $\mathrm{Mn}-\mathrm{N}$ bonding. (Figure S2) [9] The oxygen signal have the tail toward higher energy, implying $\mathrm{OH}^{-}$species on the surface. ${ }^{[10]}$ Intense nitrogen signals were detected in $\operatorname{MnON}(1)$ and $\operatorname{MnON}(2)$ when compared with the relatively weak signal found in $\mathrm{MnON}(3)$.

The anion occupancy and Mn valence calculated from chemical analysis show the same qualitative trend as those derived from XRD and X-ray absorption; an increase in nitrogen content from $\mathrm{MnON}(3)$ to $\mathrm{MnON}(1)$ increases anion occupancy, and correlates with increased Mn valence. The increase of anion occupancy by enriching nitrogen increases in the lattice parameters of rocksalt-based structures. Nonetheless, the quantitative values of anion occupancy and Mn valence calculated from chemical analysis deviate 
approximately 0.1 from those derived from XRD and X-ray absorption. These deviations can be attributed to impurity phase(s), absorption layer indicated by XPS, a possible cation vacancy as well as the error of estimated $\mathrm{Mn}$ valence using oxide standards. The relationship among nitrogen content, vacancy and lattice parameters is similar to those reported in manganese nitrides: $\mathrm{Mn}_{6} \mathrm{~N}_{5.26}(a=0.42193(1) \mathrm{nm} \quad c=0.41287(1)$ $\mathrm{nm})$ and $\mathrm{Mn}_{3} \mathrm{~N}_{2}(a=0.42193 \mathrm{~nm}, c=1.2124(1) \mathrm{nm}) .{ }^{[6]}$ Small differences in lattice parameters found between manganese oxynitrides and reported manganese nitrides can be related to slightly deviant nitrogen and oxygen amounts.

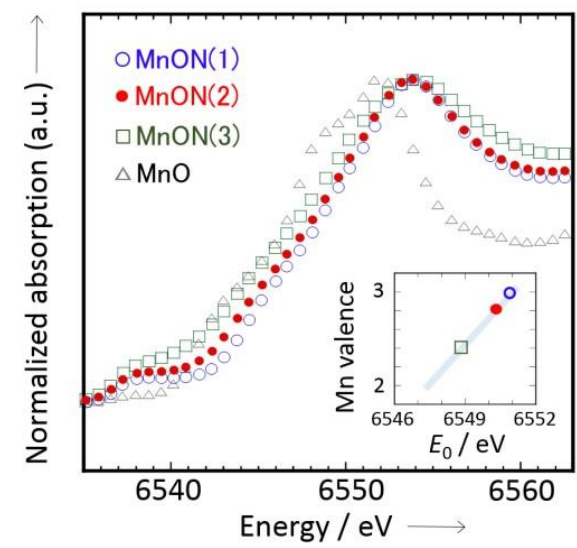

Figure 3. X-ray absorption $K$-edge of manganese oxynitrides. Inset shows the calibration line for the estimation of $\mathrm{Mn}$ valence from inflection points $\left(E_{0}\right)$ using $\mathrm{MnO}$ and $\mathrm{Mn}_{2} \mathrm{O}_{3}$ standards.

a)

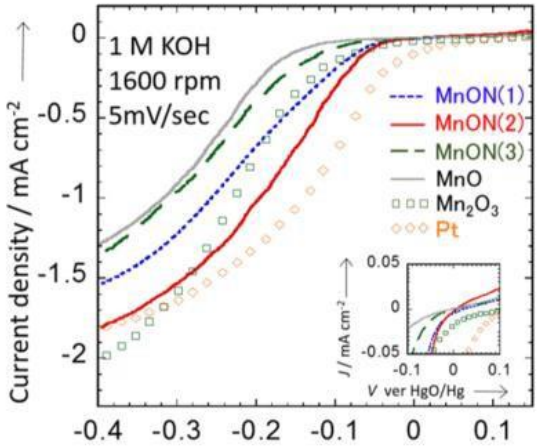

Potential / V vs. HgO/Hg electrode $\longrightarrow$

b)

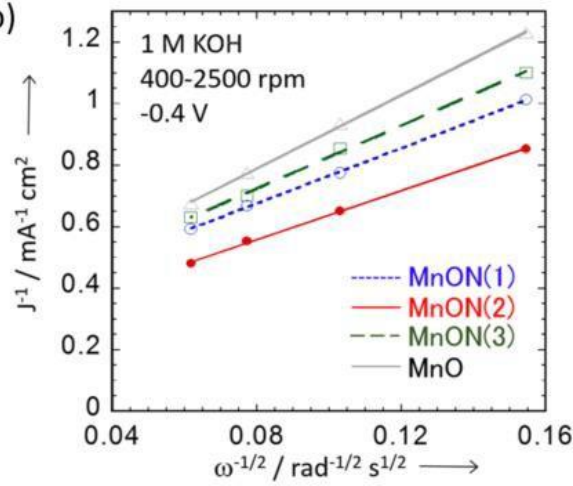

Figure 4 a) Linear sweep polarization of $\mathrm{MnON}(1), \mathrm{MnON}(2)$, $\mathrm{MnON}(3)$, and $\mathrm{MnO}$ with rotating disc electrode in $\mathrm{O}_{2}$-saturated $1 \mathrm{M}$ $\mathrm{KOH}$ solution at a sweep rate of $5 \mathrm{mV} \mathrm{sec}{ }^{-1}$. Polarization of $\mathrm{Pt} / \mathrm{C}$ and $\mathrm{Mn}_{2} \mathrm{O}_{3}$ is shown for comparison. b) Kouteky-Levich plots at -0.4 $\mathrm{eV}$ with rotation speeds of $400-2500 \mathrm{rpm}$.

The ORR activities of three manganese oxynitrides in an $\mathrm{O}_{2}$-saturated alkaline aqueous solution were examined by linear sweep polarization (Figure 4). The increasing nitrogen content in rocksalt-based structures from $\mathrm{MnO}$ through
$\mathrm{MnON}(3)$ to $\mathrm{MnON}(2)$ shifts the onset of ORR towards higher potentials (Figure $4(\mathrm{a})$ ). $\mathrm{MnON}(1)$ and $\mathrm{MnON}(2)$ show highest onsets for ORR activity. These onsets are $\sim 0.07 \mathrm{eV}$ lower than that of $\mathrm{Pt} / \mathrm{C}$, and close to that of $\mathrm{Mn}_{2} \mathrm{O}_{3}$ (inset of Figure 4(a)). In Ar-saturated $\mathrm{KOH}$ solution, less than -o.1 $\mathrm{mA} \cdot \mathrm{cm}^{-2}$ current density was detected for $\operatorname{MnON}(2)$, suggesting that ORR took place in the $\mathrm{O}_{2}$-saturated solution. Kouteky-Levich plots ${ }^{[1]}$ of the current at $-0.4 \mathrm{~V}$ at rotation speeds of 400-2500 rpm (Figure 4(b)) are linear, and the number of electrons estimated from these slopes is 3.2 for $\operatorname{MnON}(1), 3.6$ for $\operatorname{MnON}(2), 2.8$ for $\operatorname{MnON}(3)$, and 2.4 for $\mathrm{MnO}$. Thus, increased nitrogen incorporation in rocksaltbased oxynitrides reduced the overpotential of ORR and enhanced the (pseudo-)four electron reaction.

The structure-activity relationship of manganese oxynitrides can be rationalized by the octahedral motif as proposed in perovskite oxides. In perovskite oxides with metal-oxygen octahedron, nearly single-electron occupancy in the antibonding $e_{\mathrm{g}}$ states and enhanced covalency of metaloxygen bonding are beneficial in terms of the onset potential for ORR current. ${ }^{[2 d]}$ The valences of manganese in nitrogenrich $\operatorname{MnON}(1)$ and $\operatorname{MnON}(2)$, which show the highest onset potential, are close to three, thus $\mathrm{Mn}-(\mathrm{O}, \mathrm{N})$ octahedron having nearly single electron in the anitibonding $e_{\mathrm{g}}$ states is expected. Although the surface area of the aggregated oxynitride powders would affect the magnitude of current density of the ORR, it would have relatively small influence on the onset potential. Thus, the comparison between manganese oxynitrides and perovskite oxides suggests that the highest onset potential of the ORR currents in $\operatorname{MnON}(1)$ and $\operatorname{MnON}(2)$ can be explained by $\sim 1$ electron in the antibonding $e_{\mathrm{g}}$ state (Figure $\mathrm{S}_{3}$ ). Moreover, high covalency in $\mathrm{Mn}-\mathrm{N}$ bonding in nitrogen-rich $\mathrm{Mn}-(\mathrm{O}, \mathrm{N})$ octahedron can enhance the activity by shifting up the energy of the antibonding $e_{\mathrm{g}}$ state, bringing more driving force for ORR. First-principle calculation supported the expected electronic structures; antibonding states of $\mathrm{MnN}$ had less electron than those of $\mathrm{MnO}$, and the Fermi level of $\mathrm{MnN}$ located at higher energy than that of $\mathrm{MnO}$ (Figure $\mathrm{S}_{3}$ ). We note that this simple octahedral motif does not consider a possible cation vacancy, and the distribution of nitrogen/oxygen/vacancy in the anion site and the distortion of octahedron. The effect of the morphology and surface composition of oxynitride powders on the ORR activity needs further investigation. Nonetheless, using the octahedron motif, the maximum onset voltage of ORR current can be explained by approximately one electron in the $e_{\mathrm{g}}$ states and enhanced covalency in both manganese oxynitrides and perovskite oxides. Therefore, overall similarity in electron count, covalency and ORR activity between rocksalt-based manganese oxynitrides and perovskite oxides proposes that the tuning of $\mathrm{N} / \mathrm{O}$ ratios in octahedral coordination having $\sim$ electron in the $e_{\mathrm{g}}$ states can enhance the ORR catalytic activity.

In summary, low-temperature $\mathrm{NaNH}_{2}$ nitridation of manganese oxides produced oxynitrides with variable nitrogen content, depending on the oxide used. Higher $\mathrm{N}$ content increased the lattice parameters, occupancy of anion sites and the valence of manganese, and enhanced the catalytic activity in ORR. Close to single-electron occupancy of $e_{\mathrm{g}}$ states and high covalency in the Mn- $(\mathrm{O}, \mathrm{N})$ octahedral motif provide a basis for the explanation of this enhancement. This work proposes a strategy for enhancing ORR activity by optimizing the amount of nitrogen and oxygen octahedrally coordinated to a metal. 


\section{Experimental and Computational Section}

Synthesis of manganese oxynitrides followed the procedure described in previous reports on low-temperature nitridation using sodium amide. ${ }^{[8]}$ The starting oxides: $\mathrm{MnO}$ (Strem Chemicals, $99 \%$ ), $\mathrm{Mn}_{2} \mathrm{O}_{3}$ (Aldrich, $99 \%$ ), and $\mathrm{MnO}_{2}$ (Wako, $99.5 \%$ ) were ground into fine powder by a planetary ball mill at $300 \mathrm{rpm}$ for one and a half hours in an Ar-filled glove box. The corresponding powdered oxide $(0.30-0.40 \mathrm{~g})$ was mixed with $\mathrm{NaNH}_{2}$ powder (2.0 g, Aldrich, $95 \%$ ) and put in a steel crucible in the glove box. The crucible was placed in a steel autoclave, which was tightly closed and heated at $240-280{ }^{\circ} \mathrm{C}$ for 36 hours out of the glove box. Subsequently, the crucible was removed and an ethanol/water mixture was added to quench $\mathrm{NaNH}_{2}$ and byproducts. Caution! Sodium amide powder is highly sensitive to air and moisture, flammable, and can cause burns. Removing $\mathrm{NaNH}_{2}$ by water/ethanol should be performed with great care. The black precipitates were collected by filtration and further washed with ethanol/water.

The morphology of powdered samples was characterized by SEM (JEOL, JSM-6510LA) and TEM (JEOL, JEM-2010). The structures of the synthesized oxynitrides were examined using powder X-ray diffraction with $\mathrm{CuK} \alpha$ radiation (Rigaku, RINT-2000). Rietveld analysis was performed with the RIETAN-FP package, ${ }^{[11]}$ and crystal structures were drawn using VESTA. ${ }^{[12]}$ The oxygen and nitrogen content of the samples was measured by an oxygen/nitrogen combustion analyzer (Horiba, EMGA-620W). The sodium content was semi-quantitatively measured by energy-dispersive spectroscopy equipped with SEM. Surface of the powders were examined by XPS (JEOL, JPS-9200). The binding energies were corrected by reference to free carbon $(284.6 \mathrm{eV})$. The Mn- $K$ edge of $\mathrm{X}$-ray absorption near edge structure (XANES) was measured in transmission mode at the BL-9A beam line of the Photon Factory of the High Energy Accelerator Research Organization (KEK, Tsukuba). A small amount of the sample powder was mixed with boron nitride powder (Kojyundo Chem., 99\%) and then pelletized for XANES measurements.

Electrochemical measurements were performed using a rotating disk electrode in oxygen- or argon-saturated $1 \mathrm{M} \mathrm{KOH}$ aqueous solutions. Thin film electrodes were repeated drying of $1.5 \mu \mathrm{l}$ of the suspension produced by ultrasonication of oxynitrides ( $2 \mathrm{mg})$, Vulcan carbon $(2 \mathrm{mg})$, and ionomer (Tokuyama Corporation, $60 \mu \mathrm{l}$ ) in ethanol $(540 \mu \mathrm{l})$. All potentials were referenced to the $\mathrm{HgO} / \mathrm{Hg}$ electrode in $1 \mathrm{M}$ aq. $\mathrm{KOH}$. The experiment with finely powdered $\mathrm{MnO}$ and $\mathrm{Mn}_{2} \mathrm{O}_{3}$, and $\mathrm{Pt} / \mathrm{C}$ (ETEK $10 \mathrm{wt} \% \mathrm{Pt}$ ) was performed in the same way.

Non-polarized Density of States (DOS) and Crystal Orbital Hamilton Populations (COHP) ${ }^{[13]}$ were calculated by the Vienna ab initio Simulation Package ${ }^{[14]}$ and LOBSTER code ${ }^{[15]}$. The generalized gradient approximation of the PBE type and the projected-augmented wave method were used. ${ }^{[16]}$ The energy cutoff of $400 \mathrm{eV}$ was settled. Stoichiometric $\mathrm{MnO}$ and $\mathrm{MnN}$ having cubic-rocksalt structures without vacancies were utilized as initial models and their lattice parameters and atomic positions were optimized. Monkhorst-Pack k-point mesh of $12 \times 12 \times 12$ grids was used. ${ }^{[17]}$

\section{Acknowledgements}

We thank Mr. Takashi Kubota for the help with ORR measurements, Mr. Kouta Tateno for the help with combustion and XANES analyses, Prof. Yoshitaka Aoki for the discussions on the ORR, Dr. Yongming Wang for TEM observation, and the Tokuyama corporation for providing the ionomer. SEM, TEM and XPS analyses was carried out at the "Jointuse Facilities: Laboratory of Nano-Micro Material Analysis \& Laboratory of XPS analysis", Hokkaido University. XANES experiments were performed by the approval of Proposal No. 2015 G602 from the Photon Factory Advisory Committee.

Received: ((will be filled in by the editorial staff))

Published online on ((will be filled in by the editorial staff))
aX. Ge, A. Sumboja, D. Wuu, T. An, B. Li, F. W. T. Goh, T. S. A. Hor, Y. Zong, Z. Liu, ACS Catalysis 2015, 5, 46434667; bW. T. Hong, M. Risch, K. A. Stoerzinger, A. Grimaud, J. Suntivich, Y. Shao-Horn, Energy Environ. Sci. 2015, 8 , 1404-1427.

[2] aD. B. Meadowcroft, Nature 1970, 226, 847-848; bY. Matsumoto, H. Yoneyama, H. Tamura, Journal of Electroanalytical Chemistry and Interfacial Electrochemistry 1977, 83, 237-243; cY. Matsumoto, H. Yoneyama, H. Tamura Journal of Electroanalytical Chemistry and Interfacial Electrochemistry 1977, 79, 319-326; dJ. Suntivich, H. A. Gasteiger, N. Yabuuchi, H. Nakanishi, J. B Goodenough, Y. Shao-Horn, Nat Chem 2011, 3, 546-550.

[3] aD. D. Vaughn Ii, J. Araujo, P. Meduri, J. F. Callejas, M. A Hickner, R. E. Schaak, Chem. Mater. 2014, 26, 6226-6232; bR. Ohnishi, M. Katayama, D. Cha, K. Takanabe, J. Kubota, K. Domen, J. Electrochem. Soc. 2013, 160, F501-F506; cZ. Jin, P. Li, D. Xiao, Scientific reports 2014, 4, 6712; dM. Lei, J. Wang, J. R. Li, Y. G. Wang, H. L. Tang, W. J. Wang, Scientific reports 2014, 4, 6013; eA. Miura, M. E. Tague, J. M. Gregoire, X.-D. Wen, R. B. van Dover, H. c. D. Abruña, F. J. DiSalvo, Chem. Mater. 2010, 22, 3451-3456; fH. Wu, W. Chen, J. Am. Chem. Soc. 2011, 133, 15236-15239.

[4] aC. Pozo-Gonzalo, O. Kartachova, A. A. J. Torriero, P. C. Howlett, A. M. Glushenkov, D. M. Fabijanic, Y. Chen, S Poissonnet, M. Forsyth, Electrochim. Acta 2013, 103, 151160; bS. Doi, A. Ishihara, S. Mitsushima, N. Kamiya, K.-i. Ota, J. Electrochem. Soc. 2007, 154, B362; cA. Seifitokaldani, M. Perrier, O. Savadogo, J. New Mater. Electrochem. Syst. 2014, 17, 055-065; dB. Cao, G. M. Veith, R. E. Diaz, J. Liu, E. A. Stach, R. R. Adzic, P. G. Khalifah, Angew Chem Int Ed Engl 2013, 52, 10753-10757.

[5] A. Miura, K. Tadanaga, E. Magome, C. Moriyoshi, Y. Kuroiwa, T. Takahiro, N. Kumada, J. Solid State Chem. 2015 229, 272-277

[6] A. Leineweber, R. Niewa, H. Jacobs, W. Kockelmann, $J$ Mater. Chem. 2000, 10, 2827-2834.

[7] B. Eck, R. Dronskowski, M. Takahashi, S. Kikkawa, J. Mater. Chem. 1999, 9, 1527-1537.

[8] aA. Miura, T. Takei, N. Kumada, Crystal Growth \& Design 2012, 12, 4545-4547; bA. Miura, T. Takei, N. Kumada, Inorg Chem 2013, 52, 11787-11791; cA. Miura, T. Takei, N. Kumada, Journal of Asian Ceramic Societies 2014, 2, 326328.

[9] aM. A. Stranick, Surf. Sci. Spectra 1999, 6, 39-46; bI. Bertóti, Surf. Coat. Technol. 2002, 151-152, 194-203.

[10] J. Torres, C. C. Perry, S. J. Bransfield, D. H. Fairbrother, The Journal of Physical Chemistry B 2003, 107, 5558-5567.

[11] F. Izumi, K. Momma, Solid State Phenom. 2007, 130, 15-20.

[12] K. Momma, F. Izumi, J. Appl. Crystallogr. 2008, 41, 653-658.

[13] R. Dronskowski, P. E. Bloechl, The Journal of Physical Chemistry 1993, 97, 8617-8624.

[14] G. Kresse, J. Hafner, Physical Review B 1993, 47, 558-561.

[15] aV. L. Deringer, A. L. Tchougréeff, R. Dronskowski, The Journal of Physical Chemistry A 2011, 115, 5461-5466; bS Maintz, V. L. Deringer, A. L. Tchougreeff, R. Dronskowski, $J$ Comput Chem 2016, 37, 1030-1035.

[16] aP. E. Blöchl, Physical Review B 1994, 50, 17953-17979; bG. Kresse, D. Joubert, Physical Review B 1999, 59, 1758-1775; cJ. P. Perdew, J. A. Chevary, S. H. Vosko, K. A. Jackson, M. R. Pederson, D. J. Singh, C. Fiolhais, Physical Review B 1992, 46, 6671-6687.

[17] H. J. Monkhorst, J. D. Pack, Physical Review B 1976, 13, 5188-5192.

Keywords: oxynitrides;nitrides;catalysts

\section{References}


Entry for the Table of Contents (Please choose one layout)

Layout 2:

\section{Oxygen Reduction}

Akira Miura, Carolina Rosero-Navarro, Yuji Masubuchi, Mikio Higuchi, Shinichi Kikkawa, and Kiyoharu Tadanaga

Page - Page

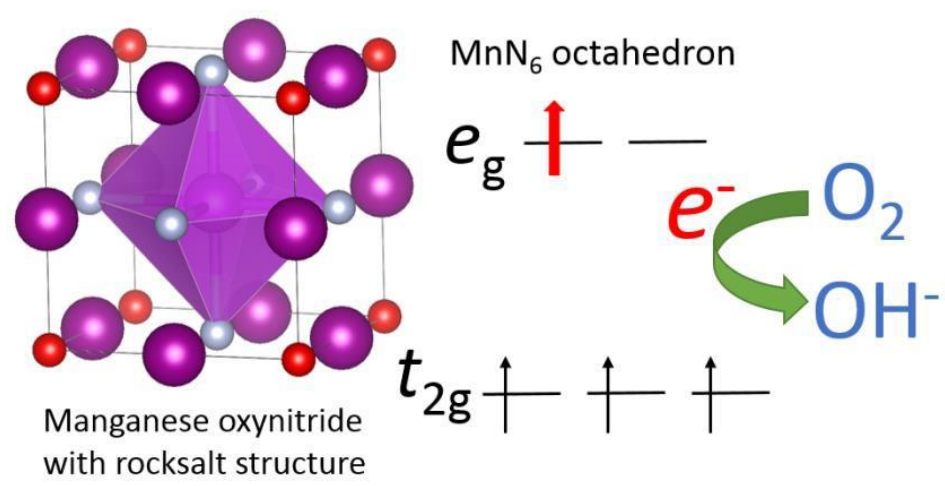

Enhanced Catalytic Activity of Nitrogen-

Rich Manganese Oxynitrides in the

Oxygen Reduction Reaction

Catalytic activity of manganese oxynitrides for oxygen reduction reaction (ORR) in an alkaline solution was investigated to clarify the effect of nitrogen on ORR activity. An increase in nitrogen content in rock-salt-based manganese oxynitrides enhanced the valence of manganese and reinforced the catalytic activity for the oxygen reduction activity in an alkaline solution. Nearly single-electron occupancy in $e_{g}$ states and high covalency in $\mathrm{Mn}-\mathrm{N}$ bonding would enhance ORR activity of manganese oxynitrides. 